DOI: $10.17805 /$ ggz.2021.3.7

\title{
Телевидение как институт культурной социализации молодежи"
}

А. О. Гришина

Московский гуманитарный университет

В статье рассматривается телевидение как один из институтов культурной сочиализачии молодого поколения, его базовые элементы, особенности и функции.

Ключевые слова: телевидение; институт социализации; молодежь; культурная сочиализация

\section{Television as an Institution of Cultural Socialization of Youth \\ A. O. Grishina \\ Moscow University for the Humanities}

The article deals with television as one of the institutions of cultural socialization of the younger generation, its basic elements, features and functions.

Keywords: television; institution of socialization; youth; cultural socialization

\section{ВВЕДЕНИЕ}

Современная молодежь существует в новой реальности, которая постигается ею не только осознанно, целенаправленно, но и стихийно, а порой принудительно. В среде, непрерывно проходящей через медиатизацию, молодому человеку нужно выстроить свою траекторию социализации. Такое направление сегодня задается одним из институтов российского общества телевидением. Различные СМИ, включая ТВ, являются неотъемлемой частью жизни человека и играют не последнюю роль в процессе его освоения окружающего мира (Жилавская, 2007.)

\section{ВЛИЯНИЕ ТЕЛЕВИДЕНИЯ \\ НА СОЦИАЛИЗАЦИЮ МОЛОДЕЖИ}

Телевидение остается одним из ключевых источников знания, сравнимый по своим досуговым свойствам с общением со сверстниками. Поэтому

\footnotetext{
* Статья подготовлена на основе доклада, представленного на IV Общероссийской (национальной) научной конференции «Моисеевские чтения» (Московский гуманитарный университет, 15-16 апреля 2021 г.).
} 
СМИ и телевидение в частности до сих пор являются формирующим механизмом социальных связей; первоисточником установок и норм «созревающей» личности молодого индивида. Процесс цифровизации медиапространства очень сильно влияет на сознание современного общества.

Это можно попытаться объяснить следующими причинами:

- Во-первых, в современном российском обществе существует переизбыток неинтеллектуальных телевизионных продуктов. Увеличение массмедийной продукции меняет структуру зрительских предпочтений.

Например, новейшие технологии позволяют создавать в видеоряде эффект «присутствия». Таким образом, простая информация, облегченная для восприятия несформированного сознания, производит наибольшее воздействие, закладывая направленные установки для деятельности в различных ситуациях.

- Во-вторых, усложнение модели просмотра телевидения приводит к усилению информационного неравенства даже среди молодежи. Основной функцией современных российских массмедиа остается донесение информации пользователям. Безусловно, телевизионные средства массовой информации - это самый распространенный пример таких массмедиа.

Однако цифровизация телевидения привела к переходу классического ТВ на платные платформы вещания, которые доступны не всем в силу своей довольно высокой стоимости. Опасность такого разрыва можно подтвердить словами М. А. Зейтунян: «...СМИ являются средством формирования "моделей” социальной реальности, важнейшим источником нормативных образцов, циркулирующих в обществе, кроме того, СМИ в значительной степени определяют нормы языка и общения» (Зейтунян, 2009: 145).

Это объясняется и тем, что СМИ как средство социализации формирует мнение большинства, а не отдельно взятой личности. Анализ литературы позволяет говорить, что это, как правило, группы людей, объединенных просмотром одного и того же источника, критически оценивающих получаемую информацию от близких, знакомых и СМИ в частности (Волков, 2015).

Исследуя вопрос о социализации молодежи в цифровой телесреде, следует обратить внимание на то, что именно молодежь находится в центре внимания как самая инициативная группа пользователей массмедиа. В первую очередь речь идет о просмотре телевидения и телевизионных каналов с помощью сети Интернет.

Актуальность изучения телевидения как института культурного развития молодого поколения состоит в том, что необходимо выявить наиболее достоверные особенности состояния (статуса) молодежи в процессе цифровизации телевидения, поскольку в постоянно изменяющемся информационном обществе крайне важно помочь молодежной аудитории социально адап- 
тироваться в реальном мире. Поскольку личность молодых людей формируется по мере развития и наращения его социального опыта и качеств, а общество всегда создает для этого определенные условия, правильным избирается путь улучшения процесса познания мира с помощью телевидения как социального института (Магомедалиева, 2014: Электронный ресурс).

Социализация как процесс культурного развития был подробно изучен А. И. Ковалевой. Она указывает на связь стадий первичной и вторичной социализаций, где вторая позволяет индивиду интерпретировать объективные факты как определенные значения (Бергер, Лукман, 1995).

Так, по трактовке А. И. Ковалевой, в этот период индивид постигает внешнюю среду посредством «другого» - окружающих его факторов. Он принимает и учится следовать общечеловеческим ценностям и правилам в ходе взаимодействия с этими факторами, направляющими его (Ковалева, 2003).

Под «другими» здесь подразумеваются семья, друзья, школа и иные организации, в число которых полноправно можно включить и телевидение, поскольку оно одновременно может считаться неким социальным знанием индивидов и элементом повседневной жизни личности.

С одной стороны, телевидение позволяет обществу накапливать целостное знание о своем развитии, с другой - удовлетворять потребности отдельно взятого человека.

Например, современное цифровое ТВ предлагает молодому зрителю передачи, предназначенные специально для компенсации его запросов: это программы о жизни «звезд» шоу-бизнеса, игры, реалити-шоу, рассчитанные на их непритязательный вкус. Таких передач особенно много на музыкальных каналах MTV и «МУЗ-ТВ», а также развлекательных каналах «СТС», «ТТ»», «Ю».

Примитивность передач с низкосортным контентом позволяет ньюсмейкерам и медиаменеджерам с наименьшими усилиями повысить рейтинг программ, привлекательность транслируемой рекламы и, как следствие, прибыль. Это дает возможность одномоментно и незаметно для самого зрителя «проникнуть в его личное пространство», понять его мотивы и интересы, использовать их для выгоды телекомпаний. В результате социализация и встроенное в нее культурное развитие молодежи претерпевает колоссальные изменения: установки, которые задает телевидение, переносятся в реальную жизнь, но не могут встроиться в нее в силу разности культурных норм, поэтому становятся причиной осложнения отношений индивида с реальным миром, поскольку не дают ему полноценного представления о нем (там же).

Наглядным примером такого негативного влияния может послужить телеканал «2×2». Отметим, что по данным медиакита, предоставленного PR- 
отделом телеканала, за 2019 год ядро аудитории (46 \%) составили люди от 18 до 36 лет, т. е. целевой аудиторией канала выступают молодые люди.

После перезапуска основу вещания на телеканале «2×2» по большей части составляют зарубежные мультипликационные и неанимационные сериалы для взрослых. Чаще это шоу пародийного и сатирического характера, такие как «Симпсоны», «Гриффины», «Американский папаша!», с абсурдным для российского телевидения юмором, поэтому такие нестандартные шутки западной мультипликации быстро подверглись критике.

Так, в начале марта 2008 г. телеканалу было вынесено первое предупреждение: «По заключению специалистов, проводивших исследование телепрограмм, анимационные сериалы “Приключения Большого Джеффа" и “Маленькие лесные друзья”... пропагандируют культ насилия и жестокости, наносят ущерб здоровью, нравственному и духовному развитию ребенка, посягают на общественную нравственность...» (Телеканалу «2×2» вынесли ... , 2008: Электронный ресурс).

В дальнейшем с различного рода разбирательствами и претензиями телеканалу приходилось сталкиваться в 2009, 2012, 2013, 2014 г.

Причем именно в 2014 г. к критике присоединилась церковь. Так 6-7 октября 2014 г. в рамках государственной программы «Формирование государственной политики в области воспитания детей - приоритетная задача семьи, общества и государства» в Москве прошел Х Съезд уполномоченных по правам ребенка в субъектах РФ. Глава общественного движения «Союз телезрителей» Константин Бендас выступил с докладом об эффективности исполнения Федерального закона «О защите детей от информации, причиняющей вред их здоровью и развитию» (№ 436-Ф3 от 29.12.2010). В качестве примера источником разрушительного влияния Бендас назвал именно телеканал « $2 \times 2 »$, сославшись на фрагмент из опубликованной информации о политике телеканала: «...создание телевидения нового поколения для вечно молодых взрослых, которые отрицают традиционные взрослые ценности и ведут активный образ жизни» (цит. по: Глава «Союза телезрителей» ... , 2014: Электронный ресурс; полужирный шрифт источника. - $A$. Г.).

В качестве положительного примера можно привести в пример известную передачу на телеканале «СТС» - «Галилео». Это телевизионная научно-популярная программа об устройстве мира, которая является русским вариантом немецкой телепередачи “Galileo" канала ProSieben. Она привлекла внимание телезрителей и телекритиков. Зрители весьма высоко оценили работу Дани Крастера, который с 22 марта 2021 г. стал ее ведущим.

Стоит отметить, что последние сезоны сняты более качественно и на современный лад: опыты стали более зрелищными и дополняются анимацией, используются сюжеты, взятые из немецкоязычного оригинала, а также 
произведенные уже в России. Также в передаче много разных рубрик, что позволяет получать информацию на разную тематику за один выпуск: от самых популярных языков программирования современности до различных бытовых советов.

Следует также отметить, что не только на «СТС» выходят познавательные передачи. «Своя игра» на «НТВ», «Что? Где? Когда?» на «Первом канале» и другие аналогичные передачи. Возможно, они не так популярны среди молодежи, однако если модернизировать их стиль и форму, сделать более современными и приближенными к телезрителю сегодняшнего дня, то список полезных для молодежи программ на телевидении начнет стремительно расширяться.

\section{ЗАКЛЮЧЕНИЕ}

Как было сказано ранее, социальная адаптация индивида происходит в процессе расширения базы его личностных качеств, дополняющиеся общественными нормами и уставами. Особенностью социализации молодежи через телевидение заключается в получении информации через СМИ.

Причем культурная социализация посредством телевидения не ограничивается только досугово-релаксационной ролью, хотя именно она позволяет молодым людям компенсировать нехватку общения с социумом или же отвлечься от бытовых забот. Даже несмотря на то, что сегодня телевизор чаще используют для фонового (избирательного) просмотра, это все равно позволяет получать некоторый объем информации, нужной для осведомленности и наиболее комфортного существования в обществе.

Телевидение включает в себя разного уровня факторы (мегафакторы, мезофакторы, микрофакторы), которые работают на определенное направление развития личности: экономику, политику, религию и другие сферы общественной жизни. Благодаря этому ТВ выполняет функцию информального образования, позволяя пользователю получать знания по самым различным вопросам, фильтровать и накапливать их. Таким образом, СМИ и особенно телевидение влияет на социализацию молодежи в нескольких проекциях:

- во-первых, телевидение выступает как институт социальной и культурной регуляции общественных систем, среди которых мы выделяем молодежь;

- во-вторых, телевидение меняет системы коммуникаций среди молодежи за счет постоянного технологического, а также культурносоциального развития среды;

- $\quad$ в-третьих, телевидение влияет на саму структуру общения, заменяя модели реального взаимодействия более новыми. 
Опираясь на эти доводы, можно сделать вывод, что цифровое телевидение приобрело большую значимость как социальный институт за счет своего как положительного, так и отрицательного культурного влияния на молодежь, в дальнейшем определяя уровень ее социализации в реальном мире.

\section{СПИСОК ЛИТЕРАТУРЫ}

Бергер, П., Лукман, Т. (1995) Социальное конструирование реальности: трактат по социологии знания : пер. с англ. М. : Медиум. 323 с.

Волков, В. А. (2015) Влияние СМИ на формирование культурных ценностей: аксиологический аспект // Молодой ученый. № 3 (83). С. 913-915.

Глава «Союза телезрителей» раскритиковал канал « $2 \times 2$ » и обвинил чиновников в неисполнении закона (2014) [Электронный ресурс] // RefNews. 16 октября. URL: https://refnews.ru/read/article/862711 [архивировано в Wayback Machine] (дата обращения: 23.05.2021).

Жилавская, И. В. (2007) Влияние СМИ на молодежь. Социологическое исследование (Томский институт информационных технологий, 2006 г.) // Медиаобразование: от теории - к практике : сб. мат. I Всеросс. науч.-практ. конф. «Медиаобразование в развитии науки, культуры, образования и средств массовой коммуникации» (Томск, 20-21 ноября 2007 г.) / сост. И. В. Жилавская ; ред. кол.: И. В. Жилавская, А. С. Ханин, Н. В. Чугаинова. Томск : Томск. ин-т информационных технологий. 322 с. С. 240-276.

Зейтунян, М. А. (2009) Роль СМИ в процессе социализации молодежи // Вестник Адыгейского государственного университета. Серия 1: Регионоведение: философия, история, социология, юриспруденция, политология, культурология. № 1. С. 142-146.

Ковалева, А. И. (2003) Концепция социализации молодежи: нормы, отклонения, социализационная траектория // Социологические исследования. № 1 (225). С. 109-115.

Магомедалиева, А. М. (2014) Социализация подростка в современном обществе [Электронный ресурс] // Материалы VI Международной студенческой научной конференции «Студенческий научный форум». URL: https://scienceforum.ru/2014/article/2014005573 [архивировано в Wayback Machine] (дата обращения: 23.05.2021).

Телеканалу «2×2» вынесли предупреждение за пропаганду насилия (2008) [Электронный ресурс] // РИА Новости. 5 марта. URL: https://ria.ru/20080305/100680462.html [архивировано в Wayback Machine] (дата обращения: 23.05.2021).

Дата поступления: 26.05.2021 2. 


\section{REFERENCES}

Berger, P. and Luckmann, T. (1995) Sotsial'noe konstruirovanie real'nosti: traktat po sotsiologii znaniia [The social construction of reality: A treatise in the sociology of knowledge] / transl. from English. Moscow : Medium Publ. 323 p. (In Russ.).

Volkov, V. A. (2015) Vliianie SMI na formirovanie kul'turnykh tsennostei: aksiologicheskii aspekt [The influence of mass media on the development of cultural values: The axiological aspect]. Molodoi uchenyi, no. 3 (83), pp. 913-915. (In Russ.).

Glava «Soiuza telezritelei» raskritikoval kanal «2×2» i obvinil chinovnikov $\mathrm{v}$ neispolnenii zakona [Head of the Union of TV Viewers criticized the channel $2 \times 2$ and accused officials of non-compliance with the law]. (2014) Ref-News, October 16. [online] Available at: https://refnews.ru/read/article/862711 [archived in Wayback Machine] (accessed 23.05.2021). (In Russ.).

Zhilavskaia, I. V. (2007) Vliianie SMI na molodezh'. Sotsiologicheskoe issledovanie (Tomskii institut informatsionnykh tekhnologii, $2006 \mathrm{~g}$.) [The influence of mass media on the youth. A sociological research (Tomsk Institute of Information Technologies, 2006)]. In: Mediaobrazovanie: ot teorii $-k$ praktike [Media education: From theory to practice] : Proceedings of the 1st All-Russian researchto-practice conference "Media Education in the Development of Science, Culture, Education and Mass Communication" (Tomsk, November 20-21, 2007) / comp. by I. V. Zhilavskaia ; editorial board: I. V. Zhilavskaia, A. S. Khanin and N. V. Chugainova. Tomsk : Tomsk Institute of Information Technologies Publ. 322 p. Pp. 240-276. (In Russ.).

Zeitunian, M. A. (2009) Rol' SMI v protsesse sotsializatsii molodezhi [The role of the mass media in the process of youth socialization]. Vestnik Adygeiskogo gosudarstvennogo universiteta. Seriia 1: Regionovedenie: filosofiia, istoriia, sotsiologiia, iurisprudentsiia, politologiia, kul'turologiia, no. 1, pp. 142-146. (In Russ.).

Kovaleva, A. I. (2003) Kontseptsiia sotsializatsii molodezhi: normy, otkloneniia, sotsializatsionnaia traektoriia [The concept of socialization of youth: Norms, deviations, socialization trajectory]. Sotsiologicheskie issledovaniia, no. 1 (225), pp. 109-115. (In Russ.).

Magomedalieva, A. M. (2014) Sotsializatsiia podrostka v sovremennom obshchestve [Socialization of a teenager in modern society]. In: Materialy VI Mezhdunarodnoi studencheskoi nauchnoi konferentsii «Studencheskii nauchnyi forum» [Proceedings of the 6th International conference "Student Research Forum"]. [online] Available at: https://scienceforum.ru/2014/article/2014005573 [archived in Wayback Machine] (accessed 23.05.2021). (In Russ.).

Telekanalu «2×2» vynesli preduprezhdenie za propagandu nasiliia [TV 
channel $2 \times 2$ was issued a warning for promotion of violence]. (2008) RIA Novosti, March 5. [online] Available at: https://ria.ru/20080305/100680462.html [archived in Wayback Machine] (accessed 23.05.2021). (In Russ.).

Submission date: 26.05.2021.

Гришина Алина Олеговна - магистрант кафедры философии, социологии и культурологии Московского гуманитарного университета. Адрес: 111395, Россия, г. Москва, ул. Юности, 5. Тел.: +7 (977) 822-49-39. Эл. адрес: Feofilat.C@yandex.ru. Научный руководитель - Антонина Ивановна Ковалева, доктор социологических наук, профессор, заведующий кафедрой философии, социологии и культурологии Московского гуманитарного университета.

GRISHINA Alina Olegovna, Master's Student, Department of Philosophy, Sociology and Culturology, Moscow University for the Humanities. Postal address: 5 Yunosti St., 111395 Moscow, Russian Federation. Tel.: +7 (977) 822-4939. E-mail: Feofilat.C@yandex.ru. Research adviser: Antonina I. Kovaleva, Doctor of Sociology, Professor, Head, Department of Philosophy, Sociology and Culturology, Moscow University for the Humanities.

Для циитирования:

Гришина A. O. Телевидение как институт культурной социализации молодежи [Электронный ресурс] // Горизонты гуманитарного знания. 2021. № 3. C. 51-58. URL: https://journals.mosgu.ru/ggz/article/view/1454 (дата обращения: дд.мм.гггг). DOI: $\underline{10.17805 / \mathrm{ggz} .2021 .3 .7}$ 